\title{
Functional deviations of the cardiovascular system in children of the Aral Sea
}

\author{
Gulnara Tashenova ${ }^{1, *}$, Riza Boranbayeva ${ }^{2}$, Aida Akhenbekova ${ }^{1}$, Gulzhan Kassenova ${ }^{1}$, \\ Lyaylim Nurlybay ${ }^{1}$ \\ ${ }^{1}$ Al-Farabi Kazakh National University, al-Farabi Ave. 71, 050040 Almaty, Kazakhstan \\ ${ }^{2}$ Scientific Center of pediatrics and child Surgery, al-Farabi Ave. 146, 050060 Almaty, Kazakhstan
}

\begin{abstract}
The study is devoted to the influence of disadvantages of the ecological disaster region Aral Sea on the state of the cardiovascular system in children. In $55.2 \%$ of cases, autonomic dysfunction was detected, mainly in girls of pre- and puberty age (80.8\%). In $39.4 \%$ of children in the Aral Sea region hypotension was diagnosed as adaptive in $81.2 \%$ and pathological hypotension in $18.8 \%$ of cases with the initial vagotonic vegetative status according to cardiointervalography (94.6\%). In children with arterial hypotension, there was a decline in the quality of life due to fatigue syndrome, cephalgia, reduced activity and deterioration of cognitive abilities. Cardiac pathology was manifested in $55.2 \%$ of cases in the form of impaired automatism of the sinus node (sinus arrhythmia, tachi and bradyarrhythmias) - 54.6\%, conduction disorders (incomplete blockade of the right leg of the bundle of His) in $43.3 \%$ of cases. The identified pathology shows the need to provide comprehensive medical and social assistance to the children of the Aral Sea, along with solving environmental and economic problems of the region.
\end{abstract}

\section{Introduction}

Ecological catastrophe of Aral is connected with extensive development of natural resources and intensive development of agricultural and economic production, which for a long period was carried out without due consideration of ecological and social consequences in the republics Of Central Asia and Kazakhstan [17-18]. The Aral Sea disaster led to a change in climatic conditions, which led to the impossibility of habitat of the flora and fauna of the region, creating unfavorable factors for the lives of people. The sea retreated almost 100 kilometers from the coastline.

Dry and hot climate, winds, water shortages, dust storms that raise and spread salt, pesticides and other toxic chemicals over hundreds of kilometers, which are used in the fields adversely affect the health of the population living in the region (19). In the atmosphere, water and soil in the epicenter of the catastrophe, excess of the maximum permissible concentrations of pollutants was noted. The content of such harmful substances as nitrogen dioxide in atmospheric air in the Kyzylorda region exceeded the maximum permissible

*Corresponding author: ertis_economika@mail.ru 
concentration by 1.3 times. In soil research, excess of the MPC in the content of phenol, pesticides, lindane, arsenic, PAV, in water and open reservoirs of Kyzylorda and Zhanakorgan was revealed. The content of $\mathrm{mg}, \mathrm{Fe}, \mathrm{U}, \mathrm{Se}, \mathrm{Cd}$ exceeded the maximum permissible maximum by 2.0 times [21-22]. A number of studies have indicated an increase in cancer, respiratory and digestive system diseases, urolithiasis, arterial hypertension, allergic diseases, among the population near the crisis zone. The ecological catastrophe that occurred in the Aral Sea region led to an increase in the mortality of children under the year living in this region, which reached in 1984-1985 in Karakalpakstan - 62, in the Bukhara region - 42.9 per 1000 born, where toxic mother milk is one of the factors [20]. The influence on growth of congenital anomalies and defects of development [23] was also noted.

The toxic effects of pesticides and toxic chemicals on the physical development of children and negative effects on cognitive functions were indicated by studies, and the concentration of polychlorinated biphenyls in blood plasma was higher than in healthy children from Northern Europe [1-4].

The instability of the genome, defined as the whole complex of changes that characterizes the transformation of a normal cell into a tumor, which was more pronounced in children in Aral. Significant positive correlations between the level of anxiety of children and the rate of division of blood cells in culture have been revealed, which is associated with the processes of early aging. The data obtained allow the authors to conclude that the high incidence of children living in the Aral Sea basin as well as increased genome instability and its individual sensitivity is the most likely consequence of poverty and malnutrition. That is, the detected changes in the health status of the examined children are highly likely to be associated not only with environmental pollution, but are the result of the (indirect) influence of socioeconomic problems. The analysis of the results of this study makes it possible to conclude that problems related to the state of human health can not be understood without taking into account all possible aspects of life, among which one of the most important is the expression of emotional stress, which determines the majority of limiting parameters of the organism, including the genome [7-9].

The human cardiovascular system is sensitive to any effects of environmental factors and changes in internal homeostasis, which ensures the functional reserves of the body. The results of studies on the effects of environmental pollution on mortality from cardiovascular diseases indicate their linear dependence, which allowed this indicator to be attributed to the indicators of a harmful response to fluctuations in the concentration of particles in the atmosphere. There are data to link this effect with the fact that when inhaling fine particles with an aerodynamic diameter of up to 2.5 microns (PM25), normal regulation of the heart on the part of the autonomic nervous system is violated, which affects the decrease in the heart rate [24].

Thus, cardiovascular pathology in ecologically unfavorable regions is caused both by congenital anomalies and developmental defects, and by violation of the regulatory mechanisms of cardiac activity. According to some data, changes on the part of the cardiovascular system in children in areas of environmental distress are more often characterized by the development of vegetative-vascular dystonia and myocardial dystrophy [5-6].

\section{Research material and methods}

A survey of 757 children (53.1 per cent of boys and 46.8 per cent of girls aged 5-17 years) was conducted in the following localities: The village of Irgiz is 250 children (boys - 122 $48.8 \%$, girls - $128-51.2 \%$ ), Shalkar - 250 (boys - $127-50.8 \%$, girls - $123-49.2 \%$ ) and Arys 
- 257 (153 (59.5\%) boys and $104(40.4 \%)$ girls). The following methods of research have been carried out:

1. Clinical examination and anthropometric methods: Weight, height and indices reflecting the degree of obesity, the formula of sexual development and physical development in children and adolescents, evaluation of muscle activity (determination of the strength and endurance of the hands to statistical strength) and psychophysiological studies: Variational pulse, definition of blood pressure.

2. Clinical-functional and instrumental methods: Objective examination of specialists (pediatrician, cardiologist), as well as fluorography, electrocardiography (ECG), cardiopulmonary (KIG).

3. Total clinical blood and urine tests, biochemical parameters: ALT, AST, total bilirubin, cholesterol, chlorides, creatinine, CRP, Fe, ferritin, glucose, total protein, transferrin, urea, mg, P, Ig a, Ig M, Ig G, Ig E.

\section{Research findings and discussion}

Features of cardiovascular system functioning can be indicators of adaptive abilities of the child organism in general and, especially, in regions with sharply continental climatic conditions and a dysfunctional environment.

In the structure of functional changes in children of the Aral Sea in 55.2\% (276) of cases there was vegetative dysfunction, which more often appeared in children of pre- and pubertal age $(78.9 \%)$, mainly in girls $(80.8 \%)$. According to the literature, vegetative dysfunction has a multifactorial gene of development, and predisposing factors can act, including foci of chronic infections, as chronic tonsillitis, caries, pharyngitis, sinusitis [10].

Among the children of the Aral Sea, the foci of chronic infections, such as chronic tonsillitis, caries, pharyngitis, were identified in $94.8 \%$ of cases. According to various literary data, vegetative disorders are diagnosed in $25-82 \%$ of children [11]. Vegetative disorders in children can give impetus to the development of serious pathological conditions - arterial hypertension, bronchial asthma, peptic ulcer, etc. [12].

Direct triggers of vegetative dysfunction in most cases are unfavorable weather conditions, climatic features, unfavorable ecological situation, imbalance of microelements, irrational nutrition, hormonal reconstruction of the pubertal period, etc. [10]. All these factors are characteristic of the Aral Sea, which could be the reason for the formation of vegetative dysfunction in children living in this region.

According to our data, the overwhelming majority (78.9\%) of children in the Aral Sea, vegetative dysfunction was manifested by vagotonia. On the part of the cardiovascular system, vegetative dysfunction in children was manifested in the form of complaints of headaches, pain in the heart, dizziness, poor memory. Arterial hypotension was detected in $39.4 \%$ (197) and arterial hypertension in $0.4 \%$ of cases in children of the studied region. $17.0 \%$ (47) reported complaints of poor tolerance airlessness, sultriness, heat, and the cold period of the year about increased chilliness algidity, especially of the hands and feet, which indicated a violation of thermoregulation. $20.6 \%$ (57) of children reported complaints of "lack" of air, dissatisfaction with breath, forced periodic deep sighs, shortness of breath at physical exercise, which is characteristic of respiratory syndrome caused by vegetative dysfunction. $14.8 \%$ (41) of children had complaints of unmotivated abdominal pain, a tendency to constipation. During the examination, these children observed marble, increased skin oil of the face, red dermographism, increased sweating of palms and feet.

Functional cardiopathy manifested mainly in the form of arrhythmias. The structure of heart rhythm disorders was dominated by sinus bradiarrhythmias - $24,6 \pm 2,7 \%$, sinus 


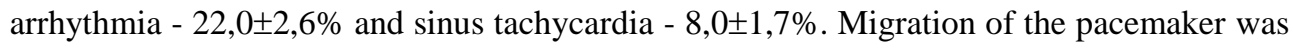
$0,6 \pm 0,4 \%$, supraventricular extrasystole $-1,3 \pm 0,8 \%$. An incomplete right bundle branch block was found among the conduction abnormalities in $43,3 \pm 3,1 \%$. The atrial ventricular conduction deceleration was $43,3 \pm 3,1 \%$. the shortening of the PQ interval and the alternation of the ventricular complex by $0.6 \%$ respectively. Metabolic disorders in ventricular myocardium are detected in $27,0 \pm 2,8 \%$ of children.

Thus, in most children of the Aral Sea, functional cardiopathy, caused by the dysfunction of the autonomic nervous system, has been identified. They were manifested in the form of a violation of the automatism of the sinus node (sinus arrhythmias, takhi- and bradyrrhic arrhythmias) and conductivity (an incomplete blockade of the right leg of the bundle), as well as vegetative-vascular dystonia. In the structure of functional deviations in children of the Aral Sea in $55.2 \%$ (276) of cases there was vegetative dysfunction, which more often appeared in children of pre- and pubertal age (78.9\%) and mainly in girls $(80.8 \%)$. In the structure of cardiovascular pathology in children of the Aral Sea arterial hypotension in $39.4 \%$ (197) and arterial hypertension in $0.4 \%$ (2) of cases, that is, there is a clear tendency to decrease blood pressure and vascular tone. Both systolic $(\leq 90)$ and diastolic $(\leq 50)$ were observed. Of these, physiological hypotension, regarded as adaptive observed in $81.2 \%$ (160) and pathological hypotension - $18.8 \%$ (37) of cases.

Arterial hypotension refers to multifactorial pathology, in the development of which play the role of hereditary predisposition, as well as the complex influence of exo- and endogenous factors [13]. In the case of family history, hereditary predisposition for arterial hypotension is more often detected on the maternal line in $81.7 \%$ (161) children of the Aral Sea. Among children with arterial hypotension in most (89.3\%) cases were girls of pre- and pubertal age. The reason for the development of arterial hypotension in the children of the Aral Sea was vegetative vascular dystonia, foci of chronic infections in $94.8 \%$, anemia in $1 / 3$ cases, features of the climatic conditions of the Aral Sea (sharply continental, in the summer - heat with temperature rise to 47-500C), poor ecological situation, as well as low material and social level of the majority of families $[14,15]$.

The nature of complaints in children with arterial hypotension had a predominantly $(90.8 \%)$ cerebral orientation in the form of headache, dizziness, drowsiness, languid in the morning. In addition to these complaints, there were complaints of dyspnea and strong heartbeats at physical loads, increased sweating of palms and feet, and increased meteosensitivity. There were frequent (20.8\%) acute vascular paroxysms, including syncopal conditions in children not only pubertal, but also prepubertal age, especially in girls $(80.5 \%)$. Fainting was most often observed during the hot season of the year. In children during the summer period, nasal bleeding was also observed at various intervals (13.7\%). The initial vegetative tone according to the results of CIG in children with physiological hypotension, the voltage index was in $90.0 \%$ of cases normal, and in $10.0 \%$ - vagotonic, that is, the voltage index was less than 30 units. In children with pathological hypotension, the original vegetative tone in most $(94.6 \%)$ cases was vagotonic.

Thus, more than one third of children in the Aral Sea have a distinct tendency to arterial hypotension. Factors of risk of arterial hypotension in children were vascular dystonia, foci of chronic infections. The quality of life in children with arterial hypotension can be very low due to constant weakness, headaches, reduced activity and other symptoms. In addition, in the adult period, in some cases, it is possible to transform stable hypotension into hypertension and in this connection, arterial hypotension in childhood acquires the features of a medical and social problem.

Arterial hypertension was only among children of pubertal age $(0.4 \%)$. Children with a tendency to increase systolic blood pressure (higher than 50-75percentile) were - $17.0 \%(85)$ of cases. They were mainly children of pre- and pubertal age (96.5\%). In all children with 
arterial hypertension, including labile, symptoms of vegetative dysfunction were noted and in $94.8 \%$ of cases - foci of chronic infections (caries, tonsillitis, pharyngitis, etc.). Children with arterial hypertension and $10.6 \%$ (9) with labile arterial hypertension were overweight (level I obesity - level 7 and level II - in 2 children).

Direct triggers of arterial hypertension and vegetative dysfunction were also features of the climatic conditions of the Aral Sea (sharply continental), an unfavorable ecological situation. The nature of complaints in children with arterial hypertension was predominantly $(67.0 \%)$ cerebral in the form of frequent, often persistent headaches, dizziness, increased fatigue. Along with these complaints, there were complaints about dyspnea and strong heartbeat at physical and psycho-emotional loads, increased sweating of palms and feet, increased meteosensitivity. $13.7 \%$ of children with arterial hypertension during the summer had nasal bleeding at different intervals. The initial vegetative tone according to the results of cardiopulography in children with a tendency to increase blood pressure index of voltage in $67.0 \%$ of cases was normal, in $33.0 \%$ - sympathetic conical, that was above 90 units.

Thus, in all children with arterial hypertension, symptoms of vegetative dysfunction were noted mainly by the sympathetic type and most of them had foci of chronic infections. Children with arterial hypertension (12.9\%) were overweight. As is known, hypertension in children and adolescents in the adult period in a number of cases is transformed into hypertension disease. $[13,15]$.

Congenital heart defects were detected in $2.6 \%$ (13) of cases in children over 5 years of age. It is known that congenital heart diseases occupy the leading place among the diseases of the cardiovascular system in children in the period of neonates and in infancy. Therefore, in children older than 5 years, patients with unperinatal congenital heart diseases are much less common [16].

Thus, arterial hypotension was detected in $39.4 \%$ and hypertension in $0.4 \%$ of cases in children of the Aral Sea. Arterial hypotension in the form of adaptive (compensatory) was observed in $81.2 \%$ and pathological hypotension in $18.8 \%$ of cases. In children with pathological hypotension, the initial vegetative tone according to cardiopintervalography data in most (94.6\%) cases was vagotonic.

In children with arterial hypotension, complaints had a predominantly $(90.8 \%)$ cerebral orientation in the form of headache, dizziness, drowsiness, languid in the morning. $20.8 \%$ of children with arterial hypotension had acute vascular paroxysms, including syncopal states.

Arterial hypertension was only among children of pubertal age $(0.4 \%)$. Children with a tendency to increase systolic blood pressure (higher than the value of 50-75percentile) were $-17.0 \%$ of cases. They were mainly children of pre- and pubertal age $(96.5 \%)$. In children with a tendency to increase blood pressure, the original vegetative tone based on the results of cardiopulography was sympathetic to the voltage index in $33.0 \%$ of the case.

In all children with arterial hypertension, including labile, symptoms of vegetative dysfunction were noted and in $94.8 \%$ of cases foci of chronic infections (caries, tonsillitis, pharyngitis, etc.) were identified. In children with arterial hypertension and $10.6 \%$ with labile arterial hypertension were overweight (I-II degree obesity).

Most children in the Aral region have functional cardiopathy in the form of a violation of sinus node automatism (sinus arrhythmias, takhi- and bradyrrhic arrhythmias) - $54.6 \%$ and conduction (an incomplete blockade of the right leg of the bundle) - $43.3 \%$ of cases.

When ECG is performed in children of the Aral region (Aktobe region of Irgys, Shalkar), we studied the frequency of detected changes. In order to achieve this goal, 184 children aged 5-17 years of age who live permanently in the region of the South Kazakhstan region (97 boys and 87 girls) were examined. The differences in sex were not confirmed statistically, which allowed them to be combined into a single unit and compare the results with the data 
of similar studies with the Kazalinskiy district and the city of Arys. The results are shown in Table 1 and 2.

Table 1. Pathological changes of ECG in children, Irgyz and Shalkar Aktobe region (309).

\begin{tabular}{|c|c|c|c|c|}
\hline \multirow{2}{*}{ Revealed pathology } & & \multicolumn{3}{|c|}{ Aktobe region (n-184+125) } \\
\hline & & Total & B-97(53\%) & G-87 (47\%) \\
\hline \multirow{3}{*}{$\begin{array}{l}\text { Increased electrical activity of the right } \\
\text { ventricle }\end{array}$} & $\mathrm{n}$ & 1 & & 1 \\
\hline & $\%$ & 0,3 & & \\
\hline & $\mathrm{m}$ & 0,6 & & \\
\hline \multirow{3}{*}{ Increased left ventricular electrical activity } & $\mathrm{n}$ & 24 & 20 & 4 \\
\hline & $\%$ & 7,8 & & \\
\hline & $\mathrm{m}$ & 1,5 & & \\
\hline \multirow{3}{*}{ Supraventricular rhythm } & $\mathrm{n}$ & 2 & 2 & \\
\hline & $\%$ & 0,6 & & \\
\hline & $\mathrm{m}$ & 0,4 & & \\
\hline \multirow{4}{*}{ Ventricular extrasystole } & $\mathrm{n}$ & 1 & & 1 \\
\hline & $\%$ & 0,3 & & \\
\hline & $\mathrm{m}$ & 0,6 & & \\
\hline & $\mathrm{m}$ & & & \\
\hline \multirow{3}{*}{ Signs of left ventricular hypertrophy } & $\mathrm{n}$ & 3 & 1 & 2 \\
\hline & $\%$ & 0,97 & & \\
\hline & $\mathrm{m}$ & 0,6 & & \\
\hline \multirow{4}{*}{ Incomplete right bundle branch block } & $\mathrm{n}$ & 13 & 10 & 3 \\
\hline & $\%$ & 4,2 & & \\
\hline & $\mathrm{m}$ & 1,3 & & \\
\hline & $\mathrm{m}$ & & & \\
\hline \multirow{3}{*}{ Violation of myocardial excitation processes } & $\mathrm{n}$ & & & \\
\hline & $\%$ & & & \\
\hline & $\mathrm{m}$ & & & \\
\hline \multirow{3}{*}{ Metabolic disorders in myocardium } & $\mathrm{n}$ & 22 & 14 & 8 \\
\hline & $\%$ & 7,1 & & \\
\hline & $\mathrm{m}$ & 1,5 & & \\
\hline \multirow{3}{*}{$\begin{array}{l}\text { Sinus tachycardia } \\
\text { moderate }\end{array}$} & $\mathrm{n}$ & 15 & 4 & 11 \\
\hline & $\%$ & 4,9 & & \\
\hline & $\mathrm{m}$ & 1,2 & & \\
\hline \multirow{3}{*}{$\begin{array}{l}\text { Sinus tachycardia } \\
\text { sharp }\end{array}$} & $\mathrm{n}$ & 16 & 3 & 13 \\
\hline & $\%$ & 5,2 & & \\
\hline & $\mathrm{m}$ & 1,4 & & \\
\hline \multirow{3}{*}{$\begin{array}{l}\text { Sinus arrhythmia } \\
\text { sharp }\end{array}$} & $\mathrm{n}$ & 6 & 4 & 2 \\
\hline & $\%$ & 1,9 & & \\
\hline & $\mathrm{m}$ & 0,8 & & \\
\hline \multirow{3}{*}{$\begin{array}{l}\text { Sinus bradycardia } \\
\text { mild }\end{array}$} & $\mathrm{n}$ & 15 & 14 & 1 \\
\hline & $\%$ & 4,9 & & \\
\hline & $\mathrm{m}$ & 1,2 & & \\
\hline \multirow{3}{*}{$\begin{array}{l}\text { Sinus bradycardia } \\
\text { moderate }\end{array}$} & $\mathrm{n}$ & 21 & 13 & 8 \\
\hline & $\%$ & 8,2 & & \\
\hline & $\mathrm{m}$ & 6,8 & & \\
\hline \multirow{4}{*}{$\begin{array}{l}\text { Sinus bradycardia } \\
\text { accute }\end{array}$} & $\mathrm{n}$ & 8 & 5 & 3 \\
\hline & $\%$ & 2,6 & & \\
\hline & $\mathrm{m}$ & 0,6 & & \\
\hline & $\mathrm{n}$ & 6 & 3 & 3 \\
\hline
\end{tabular}




\begin{tabular}{|c|c|c|c|c|}
\hline \multirow{2}{*}{$\begin{array}{l}\text { Syndrome of early repolarization of the } \\
\text { ventricles }\end{array}$} & $\%$ & 1,4 & & \\
\hline & $\mathrm{m}$ & 0,7 & & \\
\hline \multirow{3}{*}{ PQ short interval syndrome } & $\mathrm{n}$ & 14 & 11 & 3 \\
\hline & $\%$ & 4,5 & & \\
\hline & $\mathrm{m}$ & 1,2 & & \\
\hline \multirow{3}{*}{ Left anterior bundle branch block } & $\mathrm{n}$ & 4 & 2 & 2 \\
\hline & $\%$ & 1,3 & & \\
\hline & $\mathrm{m}$ & 0,6 & & \\
\hline \multirow{3}{*}{ Atrial ventricular conduction deceleration } & $\mathrm{n}$ & 2 & 1 & 1 \\
\hline & $\%$ & 0,6 & & \\
\hline & $\mathrm{m}$ & 0,4 & & \\
\hline \multirow{3}{*}{ Extension SP } & $\mathrm{n}$ & 1 & & 1 \\
\hline & $\%$ & 0,3 & & \\
\hline & $\mathrm{m}$ & 0,6 & & \\
\hline \multirow{3}{*}{ Sharp bradyarrhythmias } & $\mathrm{n}$ & 9 & & \\
\hline & $\%$ & 4,7 & & \\
\hline & $\mathrm{m}$ & 2,0 & & \\
\hline
\end{tabular}

As the study has shown, in Irgyz in $14.1 \%$ of cases recorded sinus bradycardia of different severity, which is almost 3 times less than in Arys and 2 times less than in Kazalinsky district. And sinus bradycardia was characteristic of all ages. In this case, severe bradycardia was noted in $2.7 \%$ of cases ( 5 children), moderate - in $8.2 \%$ (15 children) and mild - in $3.3 \%$ (6 children).

Disorders associated with metabolic disorders in myocardial, in children of the village Irgyz met in $2 \%$ of cases, which is significantly lower than in children of the Kazaly area ( $p$ $0.05)$.

Sinus tachycardia of moderate and pronounced severity was encountered in $9.2 \%$ of cases, which was not reliably different from other regions $(\mathrm{p}>0.05)$.

The percentage of children with signs of incomplete blockade of the right leg of the bundle of Gis in the village Irgyz and Kazaly area practically did not differ from each other, but compared to the Kazaly area was less 13-18 times ( $p>0.05)$.

Signs of increased electric activity of the left ventricle in the children of Arys and in the Kazaly district were 3-4 times more frequent than in children of the village of $\operatorname{Irgyz}(p>0,05)$.

The percentage of children with sinus arrhythmias in the three areas studied did not differ markedly. The expressed degree of arrhythmia was found in 3-4\%. These children need to monitor their ECG 24 hours a day for diagnostic arrhythmia.

The rest, the ECG violations presented in the table were recorded in single cases and were not significantly different in the districts $(\mathrm{p}>0.05)$.

Table 2. Pathological changes of ECG in children of the Aral Sea.

\begin{tabular}{|c|c|c|c|c|c|}
\hline Revealed pathology & & $\begin{array}{c}\text { Irgys } \\
\text { (Aktobe region) } \\
(\mathrm{n}-309)\end{array}$ & $\begin{array}{c}\text { Shalkar } \\
\text { (Aktobe region) } \\
(\mathrm{n}-191)\end{array}$ & $\begin{array}{c}\text { Arys } \\
(\mathrm{n}-262)\end{array}$ & $\begin{array}{c}\text { Kazaly area } \\
(\mathrm{n}-259)\end{array}$ \\
\hline \multirow{3}{*}{$\begin{array}{l}\text { Increased electrical activity } \\
\text { of the right ventricle }\end{array}$} & $\mathrm{n}$ & 1 & & 12 & 31 \\
\hline & $\%$ & 0,3 & & 4,6 & $12,0 *$ \\
\hline & $\mathrm{m}$ & 0,6 & & 1,3 & 2,0 \\
\hline \multirow{3}{*}{$\begin{array}{l}\text { Increased left ventricular } \\
\text { electrical activity }\end{array}$} & $\mathrm{n}$ & 24 & 18 & $37 * *$ & $31 * *$ \\
\hline & $\%$ & 7,8 & 9,4 & $14,1^{*}$ & 12,0 \\
\hline & $\mathrm{m}$ & 1,5 & 2,1 & 2,6 & 2,0 \\
\hline \multirow{2}{*}{$\begin{array}{l}\text { Supraventricular } \\
\text { extrasystole }\end{array}$} & $\mathrm{n}$ & 2 & 2 & 0 & 4 \\
\hline & $\%$ & 0,6 & 1,0 & 0 & 1,5 \\
\hline
\end{tabular}




\begin{tabular}{|c|c|c|c|c|c|}
\hline & $\mathrm{m}$ & 0,4 & 1,0 & 0 & 0,8 \\
\hline \multirow{3}{*}{ Supraventricular rhythm } & $\mathrm{n}$ & & 1 & & \\
\hline & $\%$ & & 0,5 & & \\
\hline & $\mathrm{m}$ & & 0,7 & & \\
\hline \multirow{3}{*}{ Ventricular extrasystole } & $\mathrm{n}$ & 1 & 1 & 1 & 0 \\
\hline & $\%$ & 0,3 & 0,5 & 0,4 & 0 \\
\hline & $\mathrm{m}$ & 0,6 & 0,7 & 0,4 & 0 \\
\hline \multirow{3}{*}{$\begin{array}{l}\text { Signs of right ventricular } \\
\text { hypertrophy }\end{array}$} & $\mathrm{n}$ & & 1 & 1 & 0 \\
\hline & $\%$ & & 0,5 & 0,4 & 0 \\
\hline & $\mathrm{m}$ & & 0,7 & 0,4 & 0 \\
\hline \multirow{3}{*}{$\begin{array}{l}\text { Signs of left ventricular } \\
\text { hypertrophy }\end{array}$} & $\mathrm{n}$ & 3 & 2 & 1 & 1 \\
\hline & $\%$ & 0,97 & 1,0 & 0,4 & 0,4 \\
\hline & $\mathrm{m}$ & 0,6 & 1,0 & 0,4 & 0,4 \\
\hline \multirow{3}{*}{$\begin{array}{l}\text { Incomplete right bundle } \\
\text { branch block }\end{array}$} & $\mathrm{n}$ & 13 & 18 & 6 & 113 \\
\hline & $\%$ & 4,2 & 9,4 & 2,3 & $43,6^{*}$ \\
\hline & $\mathrm{m}$ & 1,3 & 2,1 & 0,9 & 3,1 \\
\hline \multirow{3}{*}{$\begin{array}{l}\text { Left anterior bundle branch } \\
\text { block }\end{array}$} & $\mathrm{n}$ & & 2 & & \\
\hline & $\%$ & & 1,0 & & \\
\hline & $\mathrm{m}$ & & 1,0 & & \\
\hline \multirow{3}{*}{ QRS complex alternatives } & $\mathrm{n}$ & & & 1 & 2 \\
\hline & $\%$ & & & 0,4 & 0,8 \\
\hline & $\mathrm{m}$ & & & 0,4 & 0,6 \\
\hline \multirow{3}{*}{$\begin{array}{l}\text { Violation of myocardial } \\
\text { excitation processes }\end{array}$} & $\mathrm{n}$ & & & 1 & 21 \\
\hline & $\%$ & & & 0,4 & 8,1 \\
\hline & $\mathrm{m}$ & & & 0,4 & 1,7 \\
\hline \multirow{3}{*}{$\begin{array}{l}\text { Metabolic disorders in } \\
\text { myocardium }\end{array}$} & $\mathrm{n}$ & 22 & 12 & 24 & 72 \\
\hline & $\%$ & 7,1 & 6,3 & 9,2 & $27,0^{*}$ \\
\hline & $\mathrm{m}$ & 1,5 & 1,8 & 1,8 & 2,8 \\
\hline \multirow{3}{*}{$\begin{array}{l}\text { Sinus tachycardia } \\
\text { moderate }\end{array}$} & $\mathrm{n}$ & 15 & 15 & 11 & 20 \\
\hline & $\%$ & 4,9 & 7,8 & 4,2 & 7,7 \\
\hline & $\mathrm{m}$ & 1,2 & 1,4 & 1,2 & 1,7 \\
\hline \multirow{3}{*}{$\begin{array}{l}\text { Sinus tachycardia } \\
\text { sharp }\end{array}$} & $\mathrm{n}$ & 16 & 6 & & \\
\hline & $\%$ & 5,2 & 3,1 & & \\
\hline & $\mathrm{m}$ & 1,4 & 1,3 & & \\
\hline \multirow{3}{*}{ Sinus arrhythmia } & $\mathrm{n}$ & 6 & & 65 & 57 \\
\hline & $\%$ & 1,9 & & 24,8 & 22,0 \\
\hline & $\mathrm{m}$ & 0,8 & & 2,7 & 2,6 \\
\hline \multirow{3}{*}{$\begin{array}{l}\text { Sinus bradycardia } \\
\text { mild }\end{array}$} & $\mathrm{n}$ & 15 & 7 & & \\
\hline & $\%$ & 4,9 & 3,4 & & \\
\hline & $\mathrm{m}$ & 1,2 & 1,3 & & \\
\hline \multirow{3}{*}{$\begin{array}{l}\text { Sinus bradycardia } \\
\text { moderate }\end{array}$} & $\mathrm{n}$ & 21 & 7 & 106 & 64 \\
\hline & $\%$ & 8,2 & 3,7 & 40,5 & 24,7 \\
\hline & $\mathrm{m}$ & 6,8 & 1,3 & 1,3 & 2,7 \\
\hline \multirow{3}{*}{$\begin{array}{l}\text { Sinus bradycardia } \\
\text { accute }\end{array}$} & $\mathrm{n}$ & 8 & 2 & & \\
\hline & $\%$ & 2,6 & 1,0 & & \\
\hline & $\mathrm{m}$ & 0,6 & 1,0 & & \\
\hline \multirow{3}{*}{$\begin{array}{llr}\begin{array}{l}\text { Syndrome } \\
\text { repolarization } \\
\text { ventricles }\end{array} & \text { of } & \begin{array}{r}\text { early } \\
\text { the }\end{array} \\
\end{array}$} & $\mathrm{n}$ & 6 & 4 & 9 & 7 \\
\hline & $\%$ & 1,4 & 2,1 & 3,4 & 2.7 \\
\hline & $\mathrm{m}$ & 0,7 & 1,4 & 1,1 & 1.0 \\
\hline \multirow{3}{*}{ PQ short interval syndrome } & $\mathrm{n}$ & 14 & 10 & 9 & 2 \\
\hline & $\%$ & 4,5 & 5,2 & 3,4 & 0.8 \\
\hline & $\mathrm{m}$ & 1,2 & 1,7 & 1,1 & 0,6 \\
\hline The Vagotonic type of ECG & $\mathrm{n}$ & & & 33 & 16 \\
\hline
\end{tabular}




\begin{tabular}{|c|c|c|c|c|c|}
\hline & $\%$ & & & 12,6 & 6,2 \\
\hline & $\mathrm{m}$ & & & 2,1 & 1,5 \\
\hline \multirow{3}{*}{$\begin{array}{l}\text { Atrial ventricular } \\
\text { conduction deceleration }\end{array}$} & $\mathrm{n}$ & 2 & & 3 & 3 \\
\hline & $\%$ & 0,6 & & 1,1 & 1.2 \\
\hline & $\mathrm{m}$ & 0,4 & & 0,6 & 0.7 \\
\hline \multirow{3}{*}{ Rhythm of coronary sinus } & $\mathrm{n}$ & & & 1 & 0 \\
\hline & $\%$ & & & 0,4 & 0 \\
\hline & $\mathrm{m}$ & & & 0,4 & 0 \\
\hline \multirow{3}{*}{$\begin{array}{l}\text { Left anterior bundle branch } \\
\text { block }\end{array}$} & $\mathrm{n}$ & 4 & 2 & & \\
\hline & $\%$ & 1,3 & 1,0 & & \\
\hline & $\mathrm{m}$ & 0,6 & 1,0 & & \\
\hline \multirow{3}{*}{ Extension SP } & $\mathrm{n}$ & 1 & & & \\
\hline & $\%$ & 0,3 & & & \\
\hline & $\mathrm{m}$ & 0,6 & & & \\
\hline \multirow{3}{*}{ Sharp bradyarrhythmias } & $\mathrm{n}$ & 9 & & & \\
\hline & $\%$ & 4,7 & & & \\
\hline & $\mathrm{m}$ & 2,0 & & & \\
\hline
\end{tabular}

\section{Conclusion}

According to our data, in the structure of functional deviations from the cardio vascular system in children of the Aral Sea in 55.2\% (276) of cases, vegetative dysfunction occurred, observed mainly in girls of pre-and pubertal age (80.8\%).

Vegetative dysfunction was manifested by the type of vagotonia with clinical symptoms: Cephalgia, pain in the heart, dizziness $(78.9 \%)$, violation of thermoregulation (17\%), respiratory syndrome (a sense of "lack" air, deep sighs, dyspnea at physical load) $20.6 \%$, functional disorders of the gastrointestinal tract (14.8\%).

$39.4 \%$ of children in the Aral Sea have a distinct tendency to arterial hypotension in the form of adaptive (compensatory) hypotension in $81.2 \%$ and pathological hypotension in $18.8 \%$ of cases with initial vagotonic vegetative status according to cardiointervalography data $(94.6 \%)$. Factors of risk of arterial hypotension in children were vascular dystonia, foci of chronic infections. In children with arterial hypotension, there has been a decline in the quality of life due to fatigue syndrome, cephalus, decreased activity and other symptoms.

Functional cardiopathy in children is caused by dysfunction of the autonomic nervous system in $55.2 \%$ of cases, manifested in the form of violation of automatism of the sinus node (sinus arrhythmias, takhi- and bradyarrhythmias) - 54.6\%, violation of conductivity (incomplete blockade of the right leg of the bundle) in $43.3 \%$ of cases. According to the results of the ECG survey in children of the village Irgyz revealed less electrocardiographic violations, compared with the city of Arys and the Kazaly area (p0.05).

The research has revealed functional changes in the cardiovascular system, which have an effect on the formation of borderline or pathological health conditions in children of the Aral Sea. This demonstrates the need to provide comprehensive medical and social assistance to the children of the Aral Sea region, along with addressing the environmental and economic problems of the region.

\section{References}

1. Z. Kh. Mazhitova, Environmentally dependent diseases in children (clinic, pathomorphogenesis, diagnosis, treatment, rehabilitation), 400 (Format, Almaty, 2007) 
2. K. S. Ormantaev, Sh. N. Khusainova, Pediatrics and pediatric surgery in Kazakhstan, 3, 35-37 (2000)

3. A.K. Zhumalina, Clinical and pathogenetic mechanisms of ecological short stature in children, 32 (Almaty, 2007)

4. M. Chiba, International conference Children's Environmental Health in Central Asia, 46-51 (2005)

5. M. A. Shkolnikova, G. G. Osokina, I. V. Abdulatipova, Cardiology, 43 (8), 4-8 (2003)

6. V. A. Malievsky, Juvenile arthritis: epidemiology, medical, social and economic consequences, quality of life, 37 (Abstract, Moscow, 2006)

7. F. I. Ingel, Ecological genetics, 3, 17-19 (2005)

8. A. Ingel, Sh. Khusainova, L. Erdinger et al., Pediatrics and pediatric surgery, 4, 37-42 (2012)

9. A. A. Novik, T. I. Ionova, Study of the quality of life in pediatrics (RANS, 2008)

10. P. V. Tarkhov, Hygiene and sanitation, 5, 35-37 (2006)

11. A.M. Wayne, Autonomic disorders: clinic, treatment, diagnosis, 749 (Medical News Agency, Moscow, 2003)

12. V.Yu. Albitsky, A. A. Modestov, Ros. pediatrician. Zh., 4, 7 (2009)

13. Yu. V. Kleshchina, Ros. pediatrician. Zh., 3, 48-51 (2009)

14. N. N. Volodin, K. O. Kafarskaya, O. A. Babak, E. V. Bezenina, D. N. Degtyarev, Questions of gynecology, obstetrics and perinatology, 4 (5), 54-58 (2005)

15. N. A. Korovina, I. N. Zakharova, L. P. Gavryushova, T. M. Tvorogova, E. B. Mumladze, E. V. Skorobogatova Vegetative dystonia in children and adolescents, 60 (Medpraktika, Moscow, 2009)

16. E. V. Malysheva, Hemodynamically significant functioning ductus arteriosus and its effect on the course of perinatal diseases in deeply premature newborn, 25 (Moscow, 2008)

17. D. A. Dubinin, A. V. Derichenko, A. O. Viktorova, XXIX International Stud. Confessions, 8 (78), 8-13 (2010)

18. N. K. Kipshakbaev, V. I. Sokolov, Water resources of the Aral Sea basin-formation, distribution, water use (Collection of Water Resources of Central Asia, Almaty, 2002)

19. Ya. Ya. Khomidov, Young scientist, 9, 450-453 (2016)

20. S. A. Dzhumanov, On the question of the impact of the Aral Sea tragedy on the health of the population of Uzbekistan and the elimination of its consequences, 12-18 (Own publishing house, SPb., 2015)

21. G. P. Bespametov, Yu. A. Krotov, The maximum permissible concentration of chemicals in the environment, 390 (Chemistry, 1985)

22. T. L. Nesterova, E. I. Babkina, A. V.Konoplev, Hygiene and sanitation, 1, 66-68 (1993)

23. R. B. Isaeva, S. S. Sarsenbaeva, A. E. Dosmetov, Zh. K. Dzhaparkulova, E. V. Hen, N. S. Zhubanyshova, The medicine, 11, 82-83 (2005)

24. O. S. Starodubtseva, I. G. Khismatullina, I. I. Oranskaya, Fundamental research, 10(2), 329-332 (2012) 